Original article

\title{
Effect of education on the knowledge and attitude of intensive care unit staff towards the use of predictive disease severity scoring systems
}

\author{
Masoumeh Bagheri-Nesami', Tahereh Yaghoubi², Afshin Gholipour Baradari ${ }^{3}$, Yaser Talebiyan Keyakalayeh ${ }^{4, *}$, \\ Jamshid Yazdani Cherati ${ }^{5}$
}

(Received: 6 Jul 2015; Accepted: 13 Dec 2015)

\begin{abstract}
Background and Purpose: Severity of illness scoring systems is used for the classification of patients to receive medical services, predict the risk of mortality, determine hospital bed occupancy, and assess treatment progress. In Iran, these scoring systems are not frequently used due to the lack of knowledge of medical staff. This study aimed to evaluate the effect of education on the knowledge and attitude of intensive care unit (ICU) staff towards the use of predictive illness severity scoring systems in Imam Khomeini Hospital of Sari, Iran.

Methods: This pre-experimental study was conducted using a researcher-made questionnaire to assess the knowledge and attitude of ICU staff towards the use of illness severity scoring systems. Study population consisted of all the ICU nurses and physicians engaged in Imam Khomeini Hospital of Sari, Iran. In total, 60 participants were selected via census sampling. All the participants received training on the application of disease severity scoring systems. Knowledge level and attitude of the participants were assessed 10 days after the intervention. Data analysis was performed in SPSS V.18 using descriptive and inferential statistics, Mann-Whitney U test, and repeated measures one-way analysis of variance (ANOVA).

Results: In this study, 43 participants (72\%) were female, and the mean age of the subjects was $32.5 \pm 7.3$ years. Mean score of knowledge increased from $3 \pm 5.25$ before the intervention to $18.4 \pm 0.96$ after the intervention. With regard to attitude, mean scores reached from $100.42 \pm 11.34$ before the intervention to $122.30 \pm 9.81$ after the intervention $(\mathrm{P}=0.001)$.

Conclusion: After receiving education on the function of disease severity scoring systems, level of knowledge in the ICU nurses improved from low to high, while their attitude improved from moderate to excellent. Therefore, it is recommended that predictive patient scoring systems be included in medical and nursing curricula. Furthermore, new strategies must be considered to apply these tools in all the critical care units of the country.
\end{abstract}

Keywords: Attitude, ICU staff, Knowledge, Scoring systems, Severity of illness

\section{Introduction}

Organ dysfunction commonly occurs in the provision of care for critically ill patients and is considered as the main cause of mortalities and complications in patients admitted at intensive care units (ICUs) (1). As such, one of the major concerns in critical care research is to predict the risk of mortality and rate of complications in patients (2). Since ICU beds are costly and limited in number, patients with more severe conditions are prioritized and need the immediate attention of intensive care physicians and nurses (3).

Patient scoring systems are frequently used to classify patients based on the required treatment, care services, and medical assistance. Moreover, these tools help medical professionals to predict the risk of mortality, bed occupancy rates, and treatment progress of the patients (4). Scoring systems could also determine similar patient outcomes, clinical

\footnotetext{
${ }^{1}$ Department of Medical Surgical Nursing, Traditional and Complementary Medicine Research Center, Mazandaran University of Medical Sciences, Sari, Iran

2 Department of Nursing Management, Traditional and Complementary Medicine Research Center, Mazandaran University of Medical Sciences, Sari, Iran

${ }^{3}$ Department of Anaesthesiology, Critical Care and Cardiac Anesthesia Fellowship, Mazandaran University of Medical Sciences, Sari, Iran

${ }^{4,{ }^{*}}$ Corresponding author: Student Research Committee, Mazandaran University of Medical Sciences, Sari, Iran. Email: yasertalebyan@gmail.com

${ }^{5}$ Department of Biostatistics, School of Health Sciences, Mazandaran University of Medical Sciences, Sari, Iran
} 
decision-making, and resource allocation (5).

According to the literature, patient scoring systems could be used to verify disease illness severity and cause of prognosis (to evaluate various therapeutic interventions), assess the quality of care, manage medical records, prioritize patients, reduce treatment costs, and conduct standard research $(6,7)$.

With regard to professional management, scoring systems could be applied for the adjustment of human resources, prioritizing patients to receive special services, and prediction of hospital bed occupancy rates $(4,6)$. By using these systems, physicians will be able to report the final results of patients to their relatives with more precision and clarity. In hospitals, patient scoring systems are considered as the major criteria to assess ICU standards and compare them with international principles $(3,6,8,9)$.

According to reliable resources, there are four types of scoring systems available to predict disease severity and mortality risk, as follows: 1) Acute Physiology and Chronic Health Evaluation (APACHE; versions II, III, and IV); 2) Simplified Acute Physiologic Score (SAPS); 3) Mortality Prediction Model (MPM) and 4) Sequential Organ Failure Assessment (SOFA) (6, 7, 9). Previous studies have confirmed the efficacy of these tools in predicting various diseases $(10,11)$, and many clinical trials have used them as auxiliary methods to classify different patients (11-13).

Despite the efficacy of the aforementioned scoring systems, only a few studies in the literature review of Iranian medical centers have investigated the application of APACHE II, MPM and SAPS (14), most of which are research projects. Therefore, current findings in this regard are not considered routinely in ICUs, and the exact function of these tools remains unknown to many medical professionals.

Disease prevention and timely treatment of patients are the most essential factors in avoiding organ dysfunction. Therefore, use of scoring systems to predict disease severity and mortality risk in clinical practice could contribute to the successful monitoring of patients and reduction of mortality rates (1).

In patients admitted in the ICU, use of a valid index is of paramount importance since it leads to the most effective decision-making regarding the quality of provided services, especially nursing care. Nevertheless, in many hospitals and educational centers of Iran, healthcare providers still use traditional methods of patient evaluation, such as the monitoring of vital signs and consciousness level (4).

Although ICU nurses are required to have adequate theoretical and practical information about new patient care methods, lack of knowledge regarding the use of scoring systems prevails in the majority of these nurses (15). In Iran, several studies have been performed to evaluate the knowledge of clinical staff, especially nurses, and the results are mostly indicative of low knowledge level among these healthcare professionals. For instance, in a study entitled "Knowledge of ICU Nurses" conducted by Mohammadi et al. in Semnan Province in 2009, level of knowledge about the provision of nursing care for ICU patients was reported to range from low to moderate among the nursing staff (16). Unfortunately, this is similar to the findings of other studies in this regard (17-19).

As one of the main components of every medical team, nurses play a pivotal role in providing appropriate patient care; therefore, enhancing the quality of nursing practice is the most vital factor in accelerating patient recovery. Regular education and training are considered as the most effective response to rapid changes, which could remarkably improve the professional standards of nursing care (19).

Education is defined as the process through which a set of knowledge and skills, along with the associated habits and expertise, are conveyed to individuals in order to develop their abilities in a specific context (18). Knowledge and awareness change thought processes, attitudes and actions of individuals, and these changes are reflected in the behavior of the individual (20).

Attitude or tendency is defined as the relatively constant organization of one's beliefs about a concept or situation, which enables the individual to respond in a specific direction. Tendency is resulted from awareness. In other words, an individual's 
positive attitude towards a certain situation leads to the his/her physical and psychological preparedness for involvement in any process (21).

Nursing in ICU requires critical decision-making by applying the appropriate nursing knowledge, skills, experience, and attitude in different conditions (22).

Several studies have confirmed that expansion of knowledge will enhance the attitude and performance of nurses $(23,24)$. This study aimed to evaluate the knowledge and attitude of physicians and ICU nurses towards the use of scoring systems to predict disease severity and risk of mortality. Furthermore, we investigated the possible methods to facilitate the use of scoring systems in ICUs, as well as the efficacy of these tools in reducing treatment costs and enhancing the quality of care. By recording the obtained data, the researchers hoped to lay the grounds for future research.

\section{Materials and Methods}

In this pre-experimental study, we evaluated the effect of training about the function of predictive disease severity scoring systems on the knowledge and attitude of the nurses engaged in the ICU of Imam Khomeini Hospital of Sari, Mazandaran, Iran in 2012. Census sampling was the method of choice for selecting the participants considering the high possibility of information exchange between the participants, as well as the special condition of the ICU in Imam Khomeini Hospital affiliated to Mazandaran University of Medical Sciences. In total, 60 participants were selected for the study, including 50 nurses, seven anesthesiologists and three pulmonary disease specialists.

Data were collected using a researcher-made questionnaire consisting of demographic data, 20 items to measure knowledge, and 30 items to evaluate attitude towards the use of predictive scoring systems for disease severity and mortality risk. To measure knowledge, the questionnaire contained 20 multiplechoice items with the score range of 0-20.

Items focusing on the attitude were scored based on a five-point Likert scale (Strongly agree, Agree, Do not know, Disagree and Strongly disagree) within a score range of 30-150.

Content validity was used qualitatively to confirm the validity of the questionnaire. The questionnaire was developed based on the review of scientific research literature, and necessary adjustments were made based on the comments of 10 academic experts.

Reliability of the knowledge and attitude questionnaire was confirmed using the test-retest method. To do so, the questionnaire was initially completed by 18 ICU nurses and physicians, and this process was repeated 10 days later. Intraclass correlation coefficient of the knowledge and attitude questionnaire was estimated at 0.846 .

Initially, a pre-test was carried out to determine the level of knowledge and attitude towards the scoring systems of disease severity and mortality risk, including APACHE, SAPS, MPM, and SOFA. At this stage, the participants completed a questionnaire consisting of demographic data and level of knowledge and attitude. Afterwards, all the participants received training by the researcher in groups of 8-12 (25). In order to eliminate the effect of other data collection methods in this context, a posttest was carried out 10 days after the intervention to measure the level of knowledge and attitude (26).

In the area of knowledge, data were classified into four categories of very low (score range: $0-4$ ), low (score range: 5-9), moderate (score range: 10-15), and high (score range: 16-20). Participants with scores of $\geq 10$ were considered to have adequate knowledge regarding the function of scoring systems.

With regard to attitude, data were classified into five categories of very poor (score range: $30-54$ ), poor (score range: 55-79), moderate (score range: 80-104), good (score range: 105-129), and excellent (score range: 130-150).

Data analysis was performed in SPSS V.18 using descriptive and inferential statistics, Mann-Whitney $\mathrm{U}$ test, and repeated measures one-way analysis of variance (ANOVA).

\section{Results}

In this study, 43 participants (72\%) were female, and mean age of the study population was calculated at $32.57 .3 \pm$ years. In total, $83.33 \%$ of the participants 
Table 1. Mean scores of knowledge and attitude of participants before training based on different variables

\begin{tabular}{|c|c|c|c|c|c|}
\hline $\begin{array}{l}\text { Mean Score/ P-value } \\
\text { Variables }\end{array}$ & & Mean Score of Knowledge & Mann-Whitney U Test & Mean Score of Attitude & Mann-Whitney U Test \\
\hline \multirow{2}{*}{$\begin{array}{l}\text { Supplementary Professional ICU } \\
\text { Courses }\end{array}$} & Yes & 38.28 & \multirow{2}{*}{$\mathrm{P}=0.019$} & 43.47 & \multirow{2}{*}{$\mathrm{P}=0.001$} \\
\hline & No & 27.67 & & 25.78 & \\
\hline \multirow{2}{*}{ Attending Related Seminars } & Yes & 55.29 & \multirow{2}{*}{$\mathrm{P}=0.001$} & 44.14 & \multirow{2}{*}{$\mathrm{P}=0.026$} \\
\hline & No & 27.23 & & 28.70 & \\
\hline \multirow{2}{*}{ Personal Studies on Scoring Systems } & Yes & 45.56 & \multirow{2}{*}{$\mathrm{P}=0.001$} & 42.00 & \multirow{2}{*}{$\mathrm{P}=0.002$} \\
\hline & No & 25.02 & & 26.32 & \\
\hline \multirow{2}{*}{$\begin{array}{l}\text { Observation of Scoring System } \\
\text { Applications }\end{array}$} & Yes & 44.13 & \multirow{2}{*}{$\mathrm{P}=0.007$} & 35.00 & \multirow{2}{*}{$\begin{array}{l}\mathrm{P}=0.429 \\
\quad * \mathrm{NS}\end{array}$} \\
\hline & No & 28.4 & & 29.81 & \\
\hline \multirow{2}{*}{ Acquaintance with Scoring Systems } & Yes & 50.39 & \multirow{2}{*}{$\mathrm{P}=0.001$} & 42.86 & \multirow{2}{*}{$\mathrm{P}=0.002$} \\
\hline & No & 24.45 & & 26.74 & \\
\hline
\end{tabular}

*NS=Not significant

were nurses, and $16.67 \%$ were physicians engaged in the ICU. According to our findings, only $26.7 \%$ of the participants had experience of supplementary professional courses for the ICU department, the majority of whom were physicians. In addition, only $23.3 \%$ of the respondents were familiar with the scoring systems to predict disease severity and risk of mortality.

According to the information in Table 1 and results of Mann-Whitney U test, mean level of knowledge of the participants who had passed supplementary ICU courses (38.28), attended related seminars (55.29), had prior knowledge of scoring systems (45.56), and were acquitted with these tools (50.39) was significantly higher compared to other groups. Other data regarding the attitude of ICU nurses and physicians are presented in Table 1.

Comparison of the mean scores of knowledge and attitude before and after the intervention is presented in Table 2. Accordingly, paired t-test confirmed a significant difference in the mean of knowledge and attitude between the pre-test and post-test phase of the study ( $\mathrm{P}=0.001)$ (Table 2).

According to our findings, the majority of the participants $(81.67 \%)$ had a poor knowledge of the

Table 2. Comparison of mean scores of knowledge and attitude before and after intervention

\begin{tabular}{lccc}
\hline Variable & $\begin{array}{c}\text { Before Intervention } \\
\text { Mean } \pm \text { SD }\end{array}$ & $\begin{array}{c}\text { 10 Days after } \\
\text { Intervention } \\
\text { Mean } \pm \text { SD }\end{array}$ & $\begin{array}{c}\text { Paired } \\
\text { t-test/ } \\
\text { P-value }\end{array}$ \\
\hline Knowledge & $3 \pm 5.253$ & $18.41 \pm 0.961$ & 0.001 \\
\hline Attitude & $100.42 \pm 11.337$ & $122.30 \pm 9.807$ & 0.001 \\
\hline
\end{tabular}

predictive scoring systems for disease severity and risk of mortality before the intervention. However, 10 days after the training, all participants had a significant improvement in this regard.

Before the intervention, the knowledge level was reported to be very low, low, moderate, and high in $81.67 \%, 8.33 \%, 3.33 \%$, and $6.67 \%$ of the participants, respectively. However, after the training, high level of knowledge was reported in all the participants about the function of scoring systems.

With respect to the attitude of participants before training, $60 \%$ had moderate attitude, and $40 \%$ had good attitude towards the use of scoring systems. After the intervention, $86.67 \%$ and $13.33 \%$ of the participants improved to good and excellent attitudes, respectively.

\section{Discussion}

According to the results of this study, level of knowledge and attitude of ICU physicians and nurses had a significant difference before and after the training on the function of diseaseseverity scoring systems. One study in Taiwan was conducted to assess the knowledge and attitude of ICU nurses about the application of APACHE II scoring system. In total, 120 nurses were evaluated, and the results were indicative of the inadequate knowledge and poor attitude of these professionals towards this scoring system (27).

Findings of a similar study in this regard indicated 
that the level of knowledge on the application of different scoring systems was poor and moderate in $54 \%$ and $39 \%$ of ICU nurses, respectively. Contrary to the belief that ICU nurses gain expertise during many years of professional activity in critical care units, they mostly acquire specific skills, which are continuously used for patient care (16).

The majority of ICU nurses in the present study were young (mean age: 30 years) and had bachelor's degree (94\%). According to our findings, $96 \%$ of the nurses with bachelor's degree had very poor knowledge regarding the function of patient scoring systems. Nurses are invaluable assets of every healthcare organization, and lack of incentive for expanding knowledge in these individuals could be attributed to different factors, such as the unspecialized training and inefficient curricula of nursing in bachelor's programs, and incompetent selection of critical care nurses. Therefore, young nurses engaged in critical care units must attempt to expand their knowledge in specialized fields.

The positive attitude of ICU nurses towards the use of scoring systems despite their low level of knowledge in our study indicated that these healthcare professionals felt the need to receive relevant training, and this was probably one of the main reasons for the active cooperation of the participants in the current study. However, further research is required as to discover the other causes of this issue.

According to the results of the present study, knowledge and attitude of the nursing staff with experience of supplementary professional ICU courses was significantly higher compared to those with no history of training. This denotes that expanding professional knowledge through supplementary ICU courses encourages healthcare providers to pay attention to the quality of care, and this will positively affect their attitude. In this regard, results of other studies have suggested that experience of special training courses leads to the enhancement of professional knowledge and awareness in nurses as one of the main assets of healthcare organizations $(28,29)$.

In the present study, knowledge and attitude of participants had a significant increase 10 days after the training with regard to the use of predictive scoring systems for disease severity and risk of mortality. Correspondingly, all 60 patients $(100 \%)$ of our participants achieved perfect scores, which denoted the efficacy of training programs in improving the knowledge and attitude of nurses. This is in line with the findings of another study, which confirmed the significant effect of training on the enhancement of knowledge and performance of nurses in neonatal intensive care units (19).

In another study, researchers investigated the effect of training on the awareness and attitude of nursing students about brain death and organ donation, and the results were indicative of the positive impact of education programs on the level of knowledge and attitude of nursing students (30).

One of the factors to distinguish between ICU nurses and other nursing staff is that ICU nurses are required to have comprehensive knowledge of scientific theories with regard to nursing practice in order to provide the most effectual care for the patients (28).

Inadequate knowledge in graduate medical students could lead to uncompensable damage to the community and health system (31). Therefore, it is recommended that nurses with higher academic capability and positive attitude towards patient scoring systems be employed in critical care units. Training of nursing staff in all fields of patient care and different sectors is an inevitable, imperative issue; however, considering the particular sensitivity of critical care units, training programs are vital for the staff of these sections (16).

\section{Conclusion}

In conclusion, findings of the current study indicated that training of human resources to practice their acquired knowledge is the most fundamental approach towards organizational improvement. Medical educational programs nurture the talents of individuals, improve professional methods and techniques, result in the acquisition of knowledge and occupational skills, and prevent the waste of human and financial resources. Therefore, it is recommended that in addition to proper educational programs, healthcare professionals be provided 
with opportunities in order to apply their acquired knowledge.

\section{Conflicts of interest}

None declared.

\section{Author's contributions}

All authors participated in the preparation of the scientific proposal, data collection and drafting of the manuscript. The final manuscript was reviewed and approved by all the authors.

\section{Acknowledgements}

This article was extracted from a student's thesis conducted by a critical care nursing graduate and approved by Mazandaran University of Medical Sciences (code: 90-130, 2012). Hereby, we extend our gratitude to the Deputy of Research and Technology at Mazandaran University of Medical Sciences for the financial support of this study. We would also like to thank all the nurses and physicians engaged in the ICU of Imam Khomeini Hospital of Sari for assisting us in this research project.

\section{References}

1. Anamia EH, Grionb CM, Cardosob LT, Kaussc IA, Thomazinid MC, Zampad HB, et al. Serial evaluation of SOFA score in a Brazilian teaching hospital. Intensive Crit Care Nurs 2010; 26(2):75-82.

2. Noorizad S, Tabesh H, Mahdian M, Akbari H, Taghadosi M. Causes of mortality and morbidity in a neurosurgery ICU Kashan hospital 1999-2001. KAUMS J (Feyz) 2005; 9(2):15-20 (Persian).

3. Mohammadi H, Haghighi M. Survey relationship of mortality rate of hospitalized patients in ICU with different degrees of APACHE II. J Guilan Univ Med Sci 2006; 59(15):85-90 (Persian).

4. Soleimani MA, Masoudi R, Bahrami N, Qorbani M, Sadeghi T. Predicting mortality rate of patients in critical care units using APACHE II index. J Gorgan Univ Med Sci 2009; 11(4):64-9 (Persian).

5. Ferreira FL, Bota DP, Bross A, Me'lot C, Vincent JL.
Serial evaluation of the SOFA score to predict outcome in critically ill patients. JAMA 2001; 286(14):1754-8.

6. Longo D, Fauci A, Kasper D, Hauser S. Harrison's principles of internal medicine. $18^{\text {th }}$ ed. New York, USA: The McGraw-Hill Companies; 2011.

7. Kelley MA. Predictive scoring systems in the intensive care unit. UpToDate. Available at: URL: http://www. uptodate.com/online/content/author.do?topicKey $=\mathrm{cc}_{-}$ medi\%2F9193; 2010.

8. Le Gall JR, Lemeshow S, Saulnier F. A new simplified acute physiology score (SAPS II) based on a European/north American multicenter study. JAMA 1993; 270(24):2957-63.

9. Marino PL. The ICU book. $3^{\text {rd }}$ ed. New York: Lippincott Williams \& Wilkins; 2007.

10. Rahimzadeh P, Taghipour Anvari Z, Hassani V. Estimation of mortality rate of patients in surgical intensive care unit of Hazrat-Rasul hospital. Hakim Res J 2008; 11(1):22-8 (Persian).

11. Rose L, Baldwin I, Crawford T. The use of bed-dials to maintain recumbent positioning for critically ill mechanically ventilated patients (The RECUMBENT study): multicentre before and after observational study. Int J Nurs Stud 2010; 47(11):1425-31.

12. Hosseini M, Ramezani J. Evaluation of APACHE scoring system- either in anticipation of the separation from mechanical ventilation. J Sci Health 2007; 3(2):2-7 (Persian).

13. Hajimahmoodi M, Mojtahedzadeh M, GhaffarNatanzi N, Sadrai S, Sadeghi NA, Nadjafi A, et al. Effects of vitamin E administration on APACHE II Score in ARDS patients. DARU J Pharmaceut Sci 2009; 17(1):24-8 (Persian).

14. Hashemian SM, Jamaati HR, Malekmohammad M, Afshar EE, Alosh O, Radmand G, et al. Assessing the performance of two clinical severity scoring systems in the ICU of a tertiary respiratory disease center. Tanaffos 2010; 9(3):58-64.

15. Asgari MR, Soleimani M. Text book of nursing care in ICU, CCU, Dialysis. $16^{\text {th }}$ ed. Tehran: Boshra Publication; 2010 (Persian).

16. Mohammadi GR, Ebrahimian AA, Mahmoudi H. Evaluating the knowledge of intensive care nursing staff. Iran J Crit Care Nurs 2009; 2(1):41-6.Nickfarid L, Amiri M, Shakori M, Ghanbarian A. The knowledge of pediatric intensive care unit staffs regarding pulse oximetery. Hayat 2007; 13(4):77-87 (Persian).

17. Akhgar Araghi A, Rahimi Foroshani A, Farzane Nedjad A, Akhgar Araghi S. Pulse oximetry knowledge of medical and paramedical staff in ICUs and Ors. Payavarde Salamat 2008; 1(2):60-8 (Persian). 
18. Hadian Shirazi Z, Kargar M, Edraki M, Ghaem H, Pishva $\mathrm{N}$. The Effect of instructing the principles of endotracheal tube suctioning on knowledge and performance of nursing staff working in neonatal intensive care units in Shiraz University of medical sciences. Iran J Med Educ 2009; 9(4):365-70 (Persian).

19. Gas D, Witter B. Nursing Foundations. $2^{\text {nd }}$ ed. New York: Prentice Hall; 2007. Abbaszadeh M. Community health education and educational technology. $1^{\text {st }}$ ed. Tehran: Jamea Negar Publication; 2010 (Persian).

20. Shiri H, Nikravanmofrad M. The ICU book. $11^{\text {th }}$ ed. Tehran: Noore Danesh Publication; 2010 (Persian).

21. Firoozeh F, Tabeshian A, Karimabadeh N, Hassanzade A. Effect of education on knowledge and attitude of girl students about self breast examination. J Qom Univ Med Sci 2011; 4(4):21-6 (Persian).

22. Mohammadi ZI, Heydarnia A, Niknami S, Safari VA, Varmazyar S. The effects of educational intervention on knowledge, attitude and ergonomic behaviors. J Qazvin Univ Med Sci 2010; 14(1):33-40 (Persian).

23. Mohajer T. Principle of patient education. $2^{\text {nd }}$ ed. Tehran: Salemi Publication: 2005 (Persian).

24. Hejazi S. Understanding the principles and methods in medical research. $1^{\text {st }}$ ed. Tehran: Azad University Publication; 2007 (Persian).
25. Chen SL, Wei IL, Sang YY, Tang FI. ICU nurses' knowledge of, and attitudes towards, the APACHE II scoring system. J Clin Nurs 2004; 13(3):287-96.

26. Lindberg EB. Increased job satisfaction after small group reflection on an intensive care unit. Dimens Crit Care Nurs 2007; 26(4):163-7.

27. Scheetz LJ. Baccalaureate nursing student perceptorship program and the development of clinical competence. J Nurs Educ 1989; 28(1):29-35.

28. Abbasi Dolatabadi Z, Farahani B, Fesharaki M, Najafizadeh $\mathrm{K}$. Effect of education about brain death and organ donation on attitude and knowledge of nursing students. Iran J Crit Care Nurs 2010; 3(3):7-8 (Persian).

29. Jafari H, Vahidshahi K, Mahmudi M, Abbaskhanian A, Shahbaznezhad L, Ranjbar M, et al. Efficacy of continuing medical education on knowledge of general practitioners. Koomesh 2008; 9(4):255-62 (Persian).

30. Abbasi Dolatabadi Z, Farahani B, Fesharaki M, Najafizadeh $\mathrm{K}$. Effect of education about brain death and organ donation on attitude and knowledge of nursing students. Iran J Crit Care Nurs 2010; 3(3):7-8 (Persian).

31. Jafari H, Vahidshahi K, Mahmudi M, Abbaskhanian A, Shahbaznezhad L, Ranjbar M, et al. Efficacy of continuing medical education on knowledge of general practitioners. Koomesh 2008; 9(4):255-62 (Persian). 